\title{
1 Identity profiling of complex mixtures of peptides products by structural and mass mobility orthogonal analysis SUPPORTING INFORMATION
}

4 Said Vázquez-Leyva ${ }^{\ddagger}, \alpha$, Luis Vallejo-Castillo, ${ }^{\ddagger}$, Carlos A. López-Morales ${ }^{\alpha}$, José Enrique

5 Herbert-Pucheta ${ }^{\beta}$, L. Gerardo Zepeda-Vallejo ${ }^{\gamma}$, Marco Velasco-Velázquez ${ }^{\delta}$, Lenin Pavón ${ }^{\varepsilon}$,

6 Sonia M. Pérez-Tapia ${ }^{\alpha, \zeta, \eta,{ }^{*}}$ and Emilio Medina-Rivero ${ }^{\alpha, \theta, *}$.

7 aUnidad de Desarrollo e Investigación en Bioprocesos (UDIBI), Escuela Nacional de Ciencias Biológicas, 8 Instituto Politécnico Nacional., 11340 Mexico City, Mexico.

9 Consejo Nacional de Ciencia y Tecnología-Laboratorio Nacional de Investigación y Servicio 10 Agroalimentario Forestal, Universidad Autónoma Chapingo. 56230 Chapingo, Estado de México, Mexico.

11 'Departamento de Química Orgánica, Escuela Nacional de Ciencias Biológicas, Instituto Politécnico 12 Nacional, 11340 Mexico City, Mexico.

13 Departamento de Farmacología y Unidad Periférica de Investigación en Biomedicina Translacional 14 (CMN 20 de noviembre, ISSSTE), Facultad de Medicina, UNAM, Ciudad Universitaria, 04510 Mexico City, 15 Mexico.

16 Eaboratorio de Psicoinmunología, Dirección de Investigaciones en Neurociencias del Instituto Nacional 17 de Psiquiatría Ramón de la Fuente, 14370 Mexico City, Mexico.

18 '̌pepartamento de Inmunología, Escuela Nacional de Ciencias Biológicas, Instituto Politécnico Nacional, 1911340 Mexico City, Mexico.

20 "Laboratorio Nacional para Servicios Especializados de Investigación, Desarrollo e Innovación (I+D+i)

21 para Farmoquímicos y Biotecnológicos, LANSEIDI-FarBiotec-CONACyT, 11340 Mexico City, Mexico.

$22{ }^{\theta}$ Consultoría Integral y Biodesarrollo LEMAR S.A.P.I. de C.V, 03300 Mexico City, Mexico.

23

Table of content

\begin{tabular}{|c|c|}
\hline Number & Name \\
\hline SI.1 & $\begin{array}{l}\text { Pulse Field Gradient Stimulated Echo Diffusion Ordered Nuclear Magnetic } \\
\text { Resonance experiment (PFG-STE- } \mathrm{H}_{2} \mathrm{O} \text { (presat)-DOSY-NMR). }\end{array}$ \\
\hline SI.2 & $\begin{array}{l}\text { Set of processed diffusion coefficients (DC) for GA (blue), } \mathrm{CH} \text { (red) and hDLE } \\
\text { (black) with a difference of } 5 \times 10-11 \mathrm{~m}^{2} / \mathrm{s} \text { per diffusion coefficient. }\end{array}$ \\
\hline SI.3 & $\begin{array}{l}\mathrm{I}(\mathrm{t}) / \mathrm{I}(0) \text { experimental signal attenuation and mathematical fitting of } \mathrm{GA} \text { (blue), } \mathrm{CH} \\
\text { (red) and } \mathrm{hDLE} \text { (black) PFG-STE- } \mathrm{H}_{2} \mathrm{O} \text { (presat)-DOSY-NMR spectra as a function } \\
\text { of gradient strength }(\mathrm{G} / \mathrm{cm})^{2} \text {, at a certain delay between gradients }(\Delta=50 \mathrm{~ms}) \text { and } \\
\text { encoding - decoding gradient durations ( } \delta=2 \mathrm{~ms} \text { ). }\end{array}$ \\
\hline SI.4 & $\begin{array}{l}\text { One-dimensional water presaturation proton NMR spectra }\left\{{ }^{1} \mathrm{H}_{\text {water_presat }} \mathrm{NMR}\right\} \text { of GA } \\
\text { (blue), } \mathrm{CH} \text { (red) and hDLE (black). }\end{array}$ \\
\hline SI.5 & $\begin{array}{l}\text { Fourier Transform applied to the Free Induction Decay signals of GA (blue), } \mathrm{CH} \\
\text { (red) and hDLE (black). }\end{array}$ \\
\hline
\end{tabular}


A

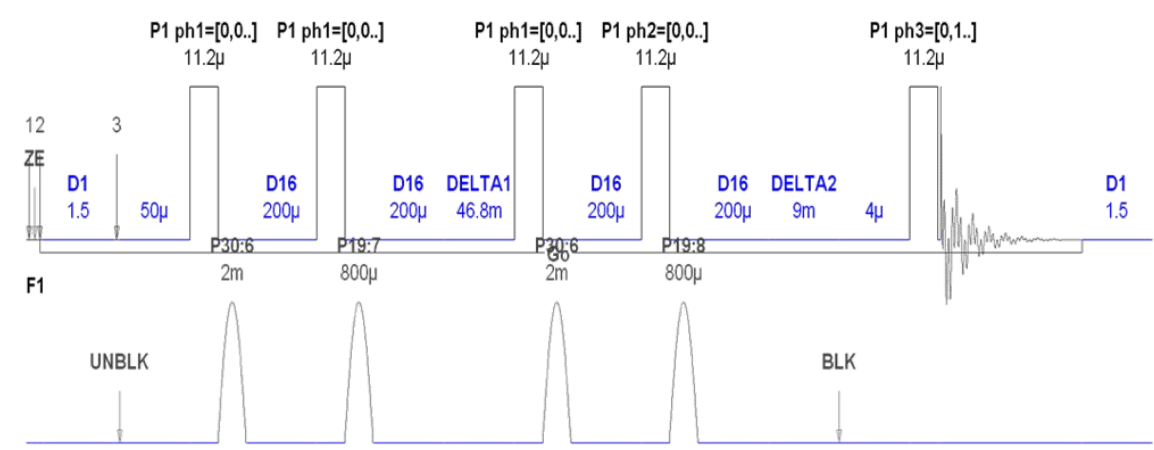

$\mathrm{B}$

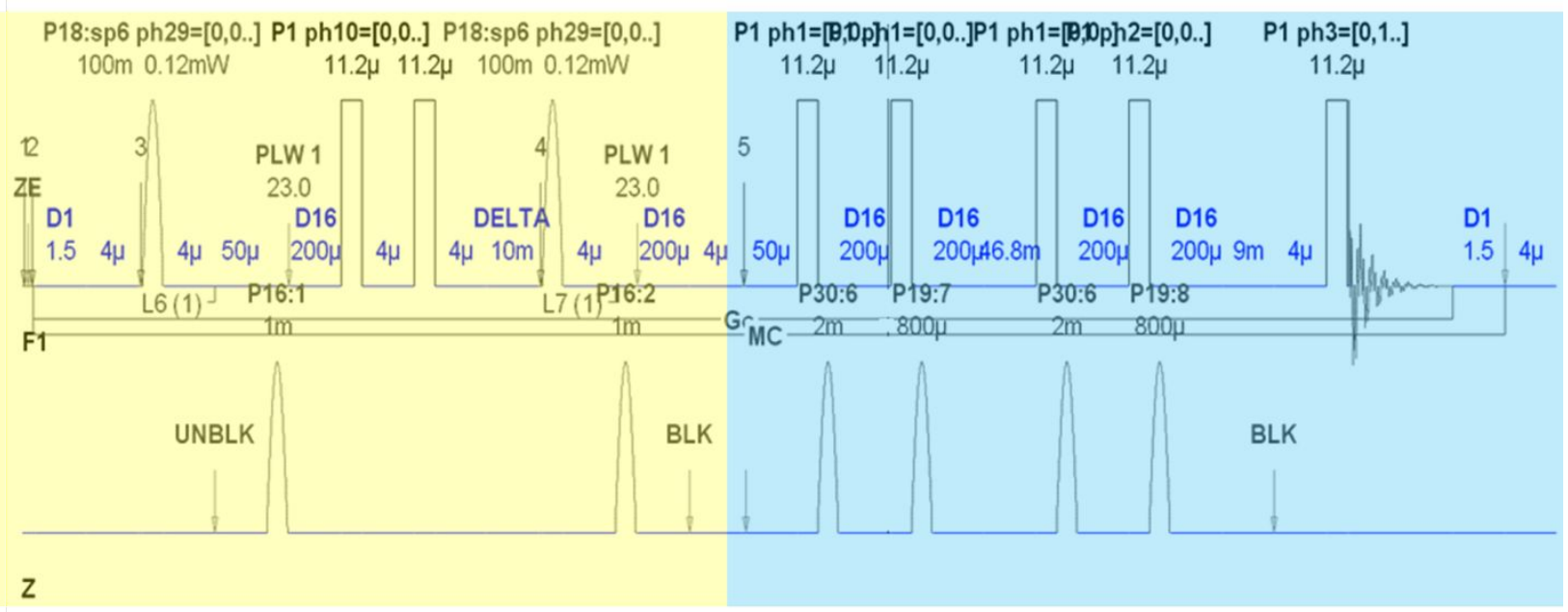

26 Figure SI.1 Pulse Field Gradient Stimulated Echo Diffusion Ordered Nuclear

27 Magnetic Resonance experiment (PFG-STE- $\mathrm{H}_{2} \mathrm{O}$ (presat)-DOSY-NMR) comprising

28 an standard module (A) for a two-dimensional experiment for diffusion coefficient

29 measurements using stimulated echo ${ }^{1}$, and a longitudinal eddy current delay (LED)

30 comprising a composite bipolar z-gradient pulse combination (g/180 / $-\mathrm{g}$ ) to

31 eliminate as possible all eddy currents ${ }^{2}$ and (B) a PFG-STE- $\mathrm{H}_{2} \mathrm{O}$ (presat)-DOSY-

32 NMR module wherein prior to the composite bipolar gradient pulses and the Gradient

33 Stimulated echo (blue area), it is inserted a home-made water-multipresaturation

34 scheme (yellow area) to eliminate buffered $-\mathrm{H}_{2} \mathrm{O}$ intense signals of $\mathrm{GA}, \mathrm{CH}$ and

35 hDLE DOSY-NMR spectra. 


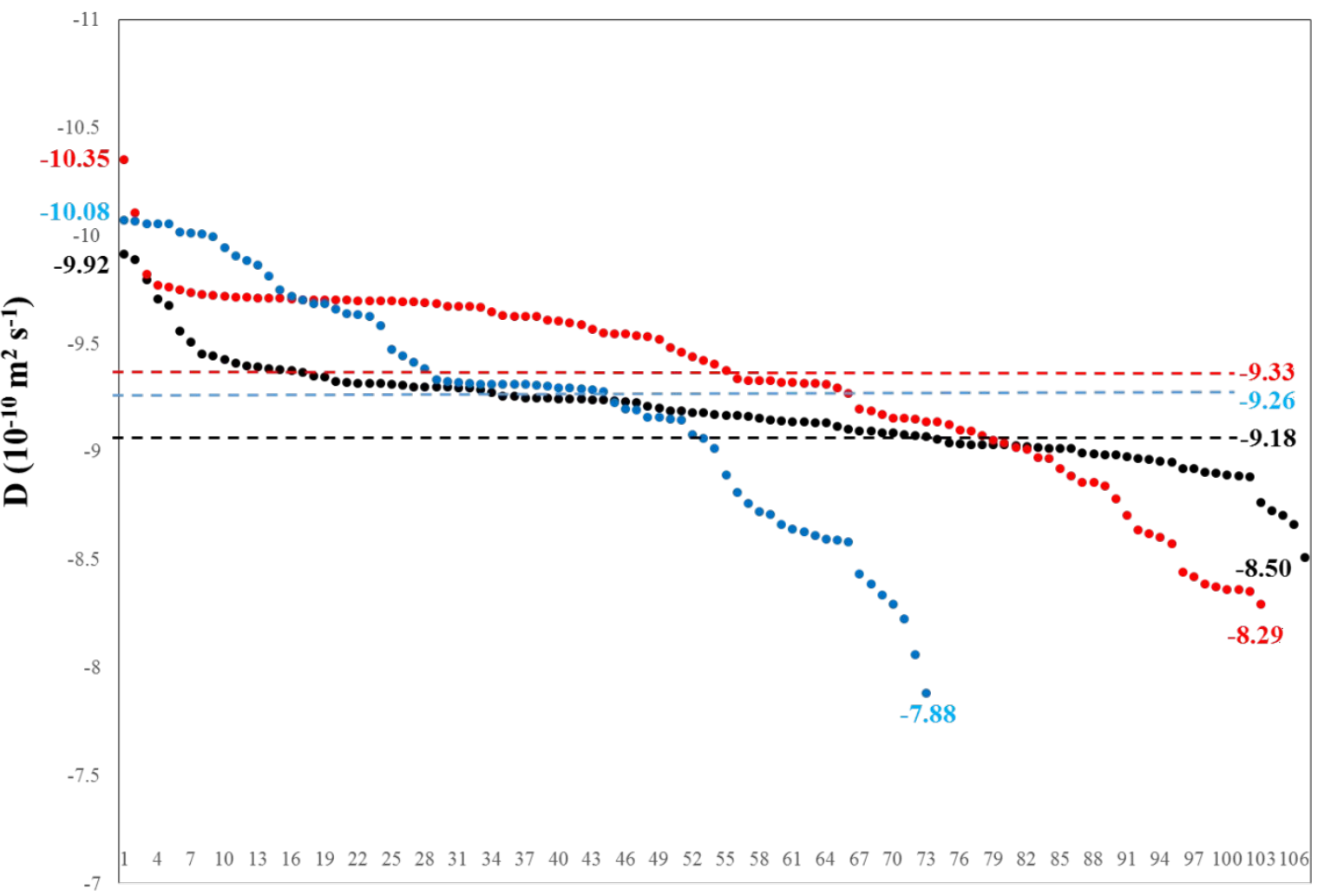

Set of processed diffusion coefficients

39 Figure SI.2. Set of processed diffusion coefficients (DC) for GA (blue), CH (red) and

40 hDLE (black) with a difference of $5 \times 10^{-11} \mathrm{~m}^{2} / \mathrm{s}$ per diffusion coefficient. Maximum,

41 minimum and median DC values are depicted within the figure. Respectively, GA,

$42 \mathrm{CH}$ and hDLE present 73, 103 and 106 different DC values, that allow to compute 43 Mean Mw and PDIs reported in Table 2 of the main text.

44 


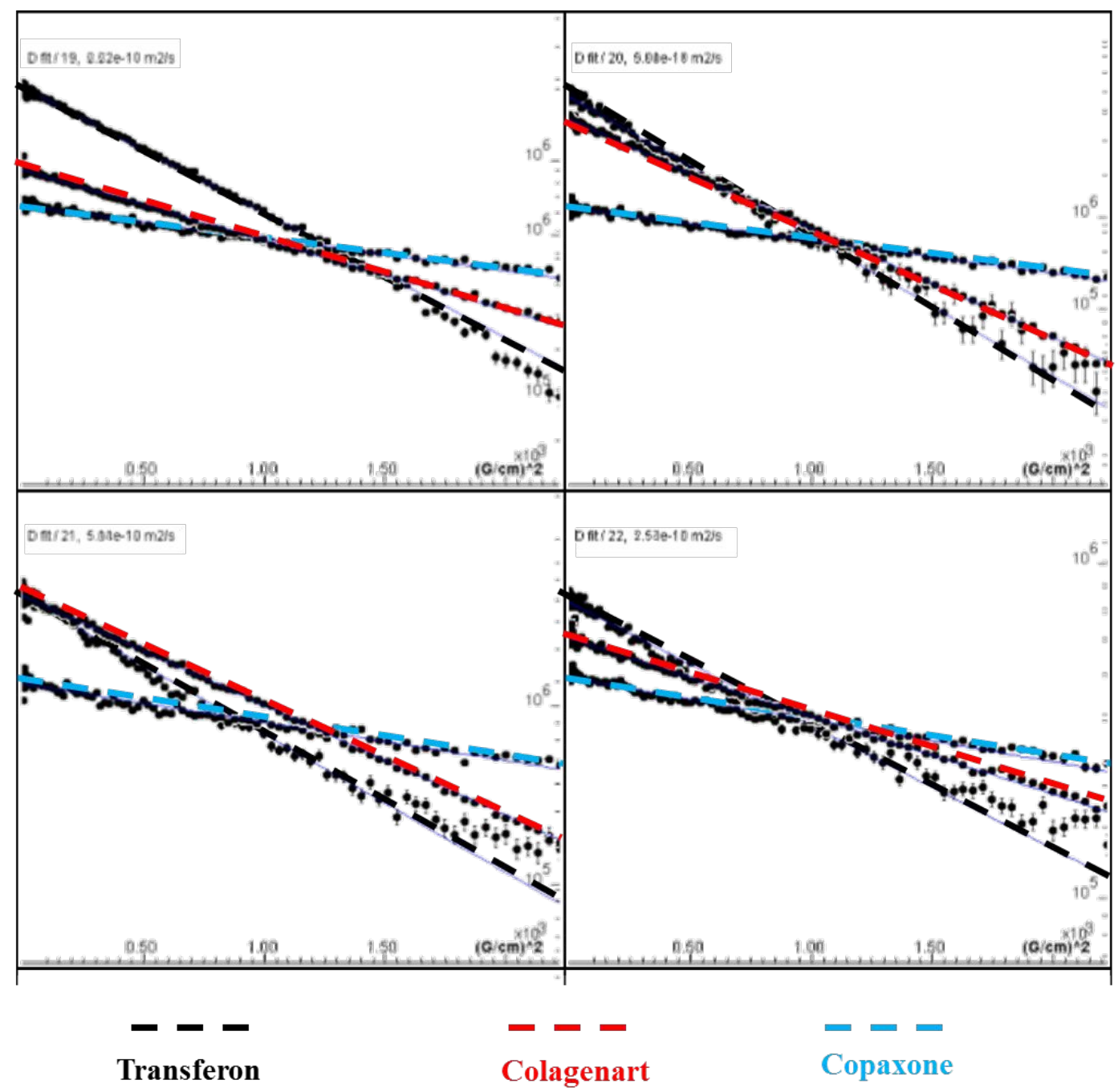

47 Figure SI.3 I(t)/I(0) experimental signal attenuation and mathematical fitting of GA 48 (blue), $\mathrm{CH}$ (red) and hDLE (black) PFG-STE- $\mathrm{H}_{2} \mathrm{O}$ (presat)-DOSY-NMR spectra as a

49 function of gradient strength $(\mathrm{G} / \mathrm{cm})^{2}$, at a certain delay between gradients $(\Delta=50$

$50 \mathrm{~ms}$ ) and encoding - decoding gradient durations ( $\delta=2 \mathrm{~ms})$. Mathematical treatment

51 with Inverse Laplace Transformation for consideration of the distribution function

52 schemed in equation (4)- main text- accurately describes signal attenuation even at 53 largest values of gradient strength, wherein multicomponent systems present 54 important deviations when a proper distribution function $P(D)$ (eq. (6), main text) is 55 not considered ${ }^{3}$. 


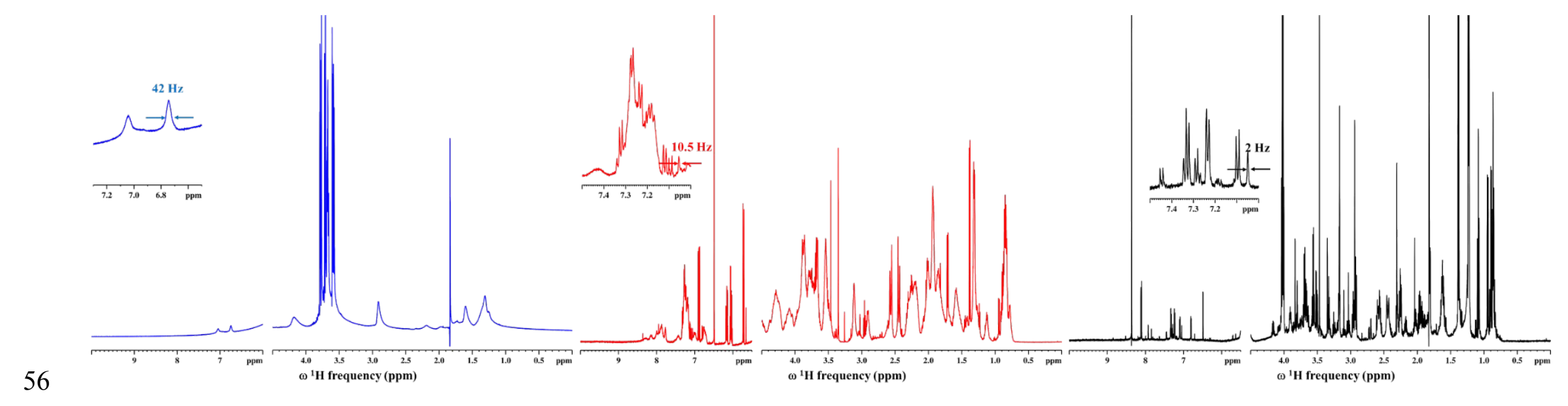

57 Figure SI.4 One-dimensional water presaturation proton NMR spectra $\left\{{ }^{1} \mathrm{H}_{\text {water_presat }}\right.$ NMR $\}$ of GA (blue), $\mathrm{CH}$ (red) and hDLE

58 (black). Spectral linewidths per complex sample are around $50 \mathrm{~Hz}$, and within the range of $10-25 \mathrm{~Hz}$ and $2.5-4 \mathrm{~Hz}$,

59 respectively. 


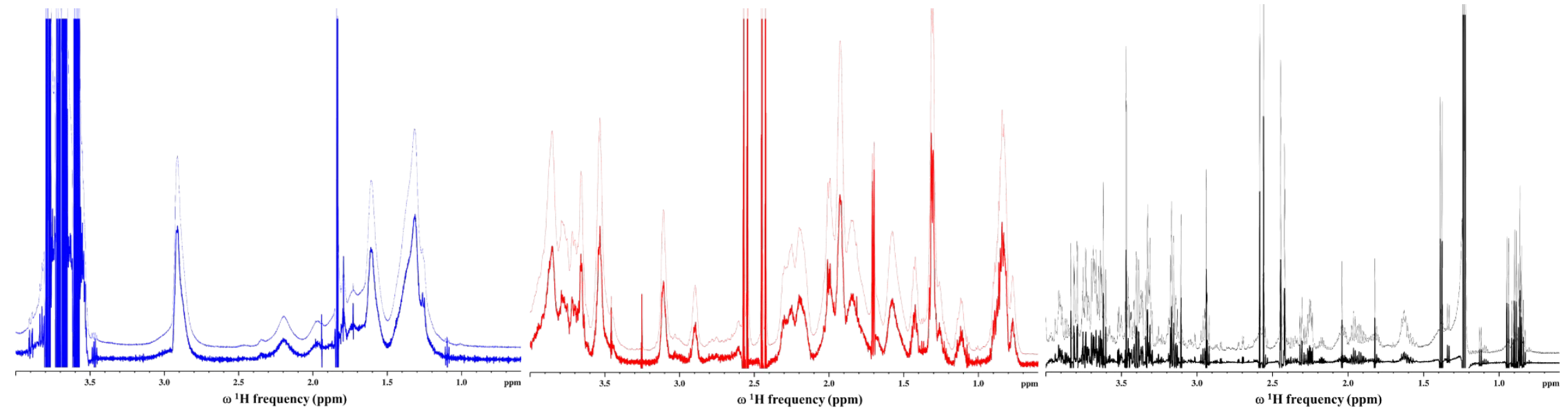

61 Figure SI.5 Fourier Transform applied to the Free Induction Decay signals of GA (blue), $\mathrm{CH}$ (red) and hDLE (black). Keen

62 selection of resonances for computing a diffusion coefficient per resonance was performed by previously applying an

63 apodization function of all $\left\{{ }^{1} \mathrm{H}_{\text {water_presat }} \mathrm{NMR}\right\}$ spectra: Light spectra within the figure shows the $\left\{{ }^{1} \mathrm{H}_{\text {water_presat }}\right.$ NMR $\}$ of $G A$,

$64 \mathrm{CH}$ and hDLE with no apodization function, whilst dark spectra shows the $\left\{{ }^{1} \mathrm{H}_{\text {water_presat }}\right.$ NMR $\}$ with a Lorentzian-to Gaussian apodization function with a line sharpening of $5 \mathrm{~Hz}$.

66

\section{REFERENCES}

68

1. E.L. Hahn, Phys. Rev. 80 (1950) 580.

69

2. A.S. Altieri, D.P. Hinton, R.A. Byrd, J. Am. Chem. Soc. 117 (1995) 7566-7667.

70

3. T.L. James, G. G. McDonald, J. Magn. Reson. 11 (1973) 58. 